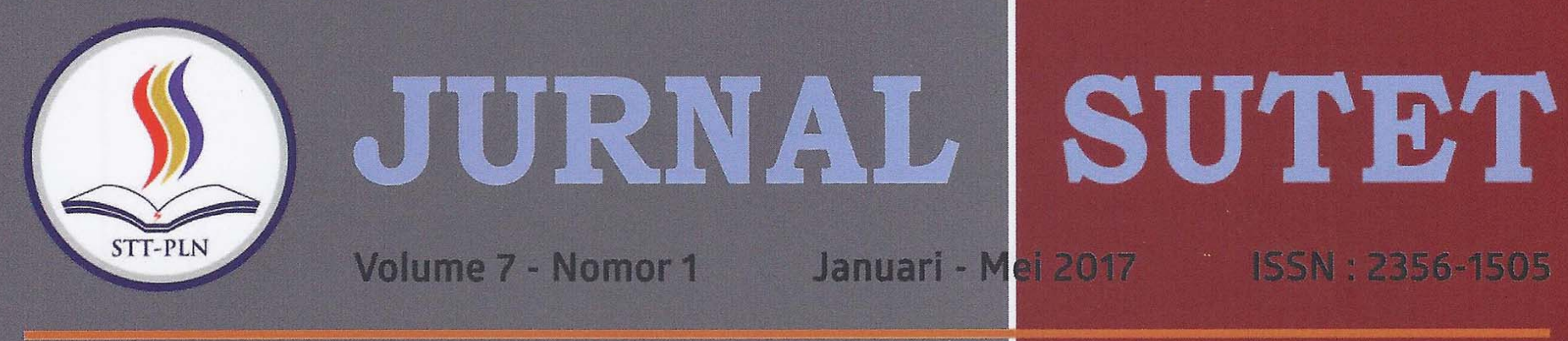

DESAIN SISTEM ALARM MOBIL BERBASIS SMS

Erlina; Hendrianto Husada; Bambang Tri Atmodjo

KELAYAKAN PENGGUNAAN PENDINGIN THERMOELEKTRIK UNTUK PENGHEMATAN DAYA LISTRIK PADA BASE TRANSCEIVER

Sunaryo; Uno Bintang Sudibyo; Supriadi Legino

WITRICITY (WIRELESS ELECTRICITY)

Aas Wasri Hasanah; Oktaria Handayani

CONCEPTUAL DESIGN FOR MITIGATING HARMONIC DISTORTION ON ESP INSTALLATION: CASE STUDY IN KAJI SEMOGA FIELD, MEDCO E\&P INDONESIA

Sandy Suryakusuma; Suprapto Atmowiranto; Dadang Darmawan

RANCANGAN RANGKAIAN ANTI BOUNCING UNTUK RANGKAIAN DIGITAL

Tasdik Darmana

STUDI POWER WHEELING DIKAWASAN INDUSTRI JABABEKA

Bimo Brillianta; Uno Bintang Sudibyo; Wildan Aripin

PEMASANGAN ARRESTER DAN ARCING HORN PADA PENGHANTAR BERISOLASI DI SUTM $20 \mathrm{kV}$ Christine Widyastuti; Andi Makkulau

PENGELOLAAN EMISI GAS LANDFILL (BIOGAS) SEBAGAI ENERGI TERBARUKAN Isworo Pujotomo; Muchamad Nur Qosim

DISAIN SISTEM PENTANAHAN PROTEKSI PETIR SISTEM MULTIPLE VERTICAL ELECTRODES PADA TERMINAL LAWE-LAWE - PERTAMINA DHP

Ibnu Hajar

ANALISA DCS (DISTRIBUTED CONTROL SYSTEM) PADA PROSES POLIMERISASI

Syarif Hidayat; Irsyadi Akbar Jay

PENGEMBANGAN TEKNOLOGI SISTEM SMART MICROGRID DI SEKOLAH TINGGI TEKNIK PLN Heri Suyanto; Agung Hariyanto

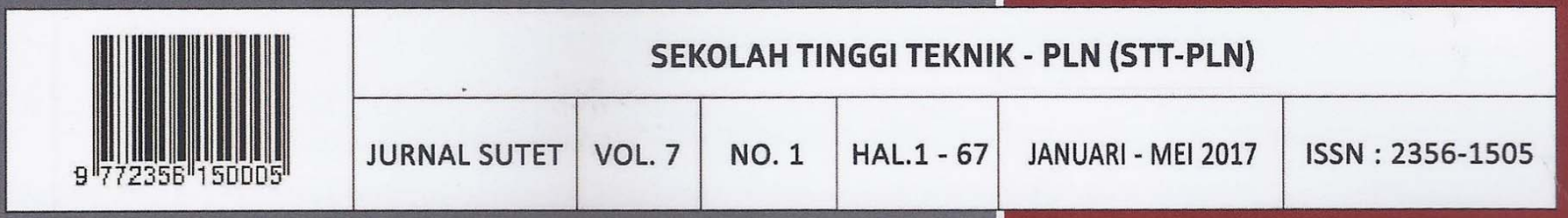




\title{
DISAIN SISTEM PENTANAHAN PROTEKSI PETIR SISTEM MULTIPLE VERTICAL ELECTRODES PADA TERMINAL LAWE-LAWE - PERTAMINA DHP
}

\author{
Ibnu Hajar \\ Teknik Elektro, Sekolah Tinggi Teknik PLN Jakarta \\ Email: ibnu.hjr@gmail.com
}

\begin{abstract}
The purpose of Grounding system design is to ensure safety for personal and equipment, andto improve fault detection of protection system.All electrical equipment should be connected to the grounding system. A system ground refers tothe point in an electrical circuit that is connected to earth. This connection point is typically at theelectrical neutral.Grounding of electrical items must be performed inside the enclosure i.e. insulated copperconductor is going to be used for earthed loop.Grounding bar of equipment, cubicle, switchboard, dedicated inside terminal boxes, lightingfittings.Lightning protection, electrical and instrument equipment should be connected to the groundingsystem separately. The objectives of lightning protection are to avoid catastrophic equipment damage and to preventpersonal injury. The energy of a lightning stroke can readily ignite flammable vapors or damageequipment.Methode of calculation used of the grounding system design of lightning protection is multiple vertical electrodes system.
\end{abstract}

Keywords:grounding, lightning protection, fault detection, multiple vertical electrodes

\begin{abstract}
Abstrak : Tujuan dari desain sistem pentanahan adalah untuk memastikan keamanan bagi manusia dan peralatan dan mengembangkan deteksi gangguan sistem proteksi. Semua peralatan listrik seharusnya terkoneksi ke sistem pentanahan. Suatu pentanahan sistem merujuk pada suatu titik dalam suatu rangkaian listrik yang terhubung ke tanah. Titik hubung ini secara tipikel ada pada saluran netral rangkaian listrik. Item-item pentanahan listrik harus dilakukan di dalam rak yaitu konduktor tembaga yang berisolasi akan digunakan sebagai konduktor loop yang ditanahkan. Bar pentanahan peralatan, kubikel, panel, dipasang di dalam kotak terminal. Proteksi petir, peralatan listrik dan instrumen harus terkoneksi ke sistem pentanahan secara terpisah. Tujuan proteksi petir adalah untuk menghindarkan/mencegah bahaya kerusakan pada peralatandan mencegah cedera pada manusia. Energi sambaran petir dapat dengan mudah menimbulkan kebakaran dan merusak peralatan. Metode perhitungan yang digunakan disain sistem pentanahan proteksi petir adalah multiple vertical electrodes system.
\end{abstract}

Kata kunci : pentanahan, proteksi petir, deteksi gangguan, multiple vertical electrodes

\section{Pendahuluan}

Kajian ini dikembangkan untuk menentukan disain sistem pentanahan dan tahanan pentanahan yang berhubungan dengan proyek Gas Fiscal Metering Replacement yang berlokasi di Pertamina DHP Balikpapan, Kalimantan Timur yang merupakan milik perusahaan Chevron Indonesia.

Perusahaan Chevron Indonesia di Balikpapan merencanakan untuk mengganti gas fiscal metering yang ada/terpasang (existing)yang berlokasi di
Pertamina DHP. Sebuah shelter baru akan dibangun dilokasi tersebut untuk semua peralatan instrumen gas fiscal metering dan flow comp akan dipindahkan ke dalam sebuah kontainer baru yang berfungsi sebagai ruang kontrol dengan lokasi yang aman.

Instalasi listrik baru akan diinstal pada gas fiscal metering tersebut seperti pada gas chromatograph, dew point analizer, penerangan (lampu-lampu), dan lain sebagainya yang berhubungan dengan gas fiscal metering dan shelter yang dibangun. Fasilitas sistem kelistrikan 
untuk proyek ini akan didisain untuk memberikan rasa aman, kelayakan dan permintaan integritas tinggi bagi fasilitas sebagaimana persyaratan MIGAS dan CES (Chevron Electrical Standard).

\section{Landasan Teori}

\section{Proteksi Petir}

Tujuan proteksi petir adalah untuk menghindari bencana kerusakan pada peralatan dan mencegah manusia dari bahaya cedera akibat sambaran petir. Energi sambaran petir dapat dengan mudah menyalakan uap yang mudah terbakar atau merusak peralatan. Sistem proteksi petir menggunakan terminal udara (batang tembaga (rods), tiang (masts), dan kawat tanah (overhead ground wires) untuk menangkap sambaran petir dan mengalirkan arus petir yang dihasilkan ke tanah melalui rangkaian impedansi rendah.

Karena sambaran petir dapat menyambar / menghantam suatu obyek yang ditanahkan dengan jarak sambaran petir (striking distance) dari titik dimana kerusakan akhir terjadi, maka zona perlindungan (the zone of protection) harus ditentukan oleh busur melingkar cekung ke atas. Radius/jari-jari busur adalah jarak sambaran petir (striking distance), dan busur harus melewati ujung tiang dan bersinggungan dengan tanah. Dan dimana bila lebih dari satu tiang yang digunakan, busur harus melewati ujung tiang yang berdekatan. (NFPA 780, Standard for the Installation of Lightning Protection System, 2008 Edition).

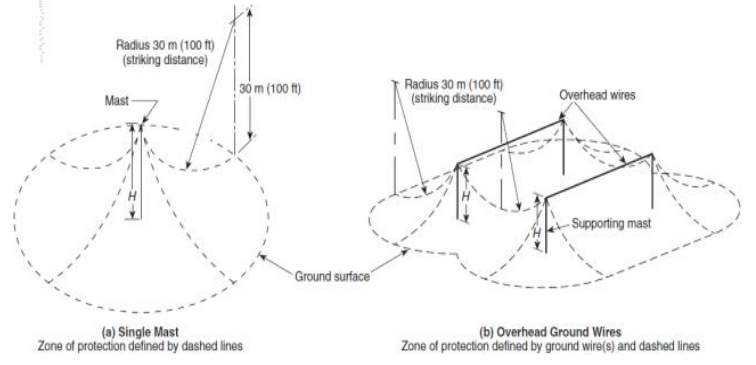

Gambar 1. Zona Perlindungan (NFPA 780, 2008 Edition)

Di lokasi proyek Gas Fiscal Metering Replacement, terdapat satu proteksi petir yang terpasang di atas tower yang dekat parkiran, tapi proteksi petir tersebut perlindungannya tidak menjangkau shelter peralatan-peralatan instrument yang baru yang akan dibangun. Pada jurnal ini tidak dapat ditunjukkan letak lokasi proteksi petir di daerah proyek dikarenakan pada saat survei dilokasi proyek tidak diizinkan membawa kamera sehingga tidak bisa mengambil gambar di lokasi.

Disain perlindungan untuk proteksi petir, dihitung berdasarkan rumus berikut:

$$
d=\sqrt{h_{1}\left(2 R-h_{1}\right)}-\sqrt{h_{2}\left(2 R-h_{2}\right)}
$$

dimana:

$d=$ jarak terproteksi horisontal

$h_{1}=$ tinggi dari tiang yang lebih tinggi

$h_{2}=$ tinggi dari tiang yang lebih rendah

$R=$ Radius / jari-jari bola bergulir $[30 \mathrm{~m}$ $(100 \mathrm{ft})]$

Untuk mencegah kilatan samping (sidefashes), jarak minimum antara tiang (mast) atau kawat tanah (overhead ground wires) dan struktur bangunan yang diproteksi harus tidak kurang dari jarak ikatan (bonding distance) atau jarak kilatan samping (sideflash distance).

Jarak kilatan samping (sideflash distance) dari tiang harus dihitung berdasarkan rumus berikut:

dimana:

$$
D=\frac{h}{6}
$$

$D=$ Jarak kilatan samping (sideflash distance) dari tiang

$h$ = tinggi struktur bangunan (atau obyek yang dihitung)

Berdasarkan pada tinggi struktur bangunan (shelter) yaitu 5 meter dan tinggi tiang dari atap struktur bangunan (shelter) yaitu 2 meter, maka total tinggi dari tiang yang lebih tinggi $h_{1}$ adalah 7 meter. Jarak terproteksi horizontal $d$ untuk tiang tunggal adalah:

$d=\sqrt{h_{1}\left(2 R-h_{1}\right)}-\sqrt{h_{2}\left(2 R-h_{2}\right)}$

$d=\sqrt{7(2 \times 30-7)}=19,26 \mathrm{~m}$

Dan jarak kilatan samping (sideflash distance) adalah 0,83 $\mathrm{m}$.

Panjang struktur bangunan yang harus dilindungi oleh proteksi petir adalah 
21 meter (lihat gambar 2, gambar dokumen LL-PP-STR-PVD-SMUC1148409_08-00001-00- Shelter Roof Plan, Gutter and Detail), maka proteksi petir yang harus dipasang adalah 2 unit, dan itu harus dipasang atap struktur bangunan (shelter).

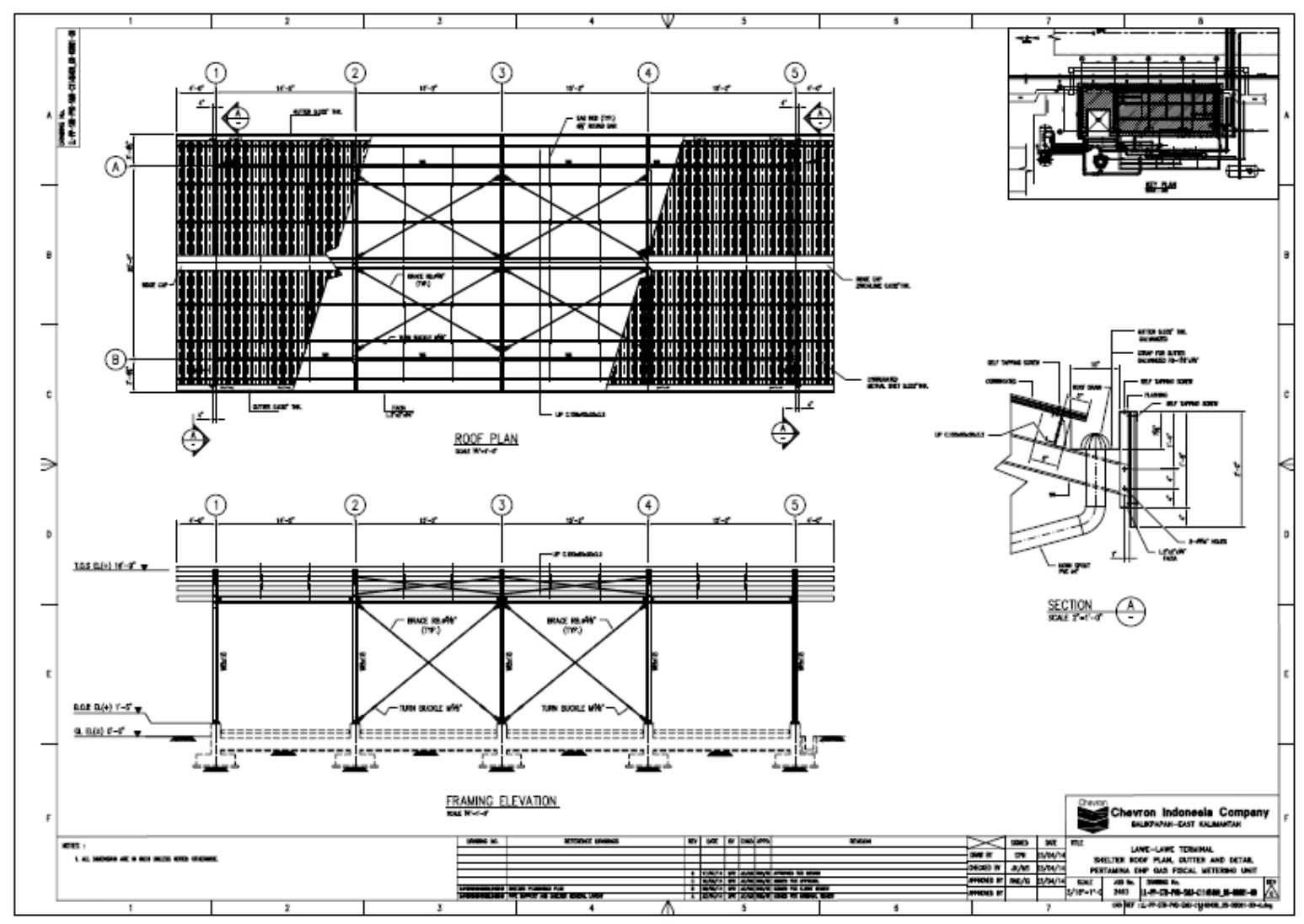

Gambar 2. Shelter Roof Plan, Gutter and Detail

\section{Metode Penelitian}

Tahapan yang dilakukan dalam penelitian ini adalah melakukan survei lapangan, kajian pustaka dan pembuatan laporan. Pada saat survei lapangan yaitu mengecek sistem proteksi petir yang terpasang, mengecek sistem pentanahan terpasang untuk shelter gas metering. Pada kajian pustaka yaitu mencari bukubuku, artikel-artikel dan standar-standar yang berkaitan dengan obyek penelitian dan kemudian membuat laporan disain berdasarkan kondisi dilapangan dengan menstandarisasi disain proteksi petir berdasarkan standar-standar yang ditentukan seperti NFPA (National Fire Protection Association) dan CES (Chevron Electrical Standar).

\section{Hasil dan Pembahasan}

\section{a. Metode Perhitungan}

Ada dua disain sistem pentanahan yang umum digunakan yaitu kombinasi horizontal elektroda (grid dengan konduktor yang diikatkan pada batang baja (grid with bar copper stranded conductor) dan elektroda vertikal (rod) dan penggunaan elektoda vertikal yang banyak (multiple vertical electrode).

Kombinasi horizontal dan vertikal adalah biasanya digunakan untuk substation dan daerah pabrik/bangunanbangunan dimana peralatan-peralatan tersebar pada daerah yang luas (distributed large area). Dan metode lain, multiple vertical electrodes yaitu biasanya digunakan untuk pentanahan instrumentasi.

Berdasarkan pada kebutuhan untuk sistem pentanahan ini, maka dipilih disain multiple vertical electrodes. 
Untuk disain sistem pentanahan proteksi petir ini, nilai resistansi tanah dapat dihitung dan bergantung pada tipe elektroda dan resistivitas tanah. Resistivitas tanah disini diasumsikan dikarenakan tidak ada data resistivitas tanah yang bisa diperoleh dari perusahaan. Untuk memastikan bahwa disain perhitungan yang dilakukan memenuhi persyaratan yang berhubungan dengan fakta lapangan di Pertamina DHP, maka resistivitas tanah diambil dari nilai ekstrim dengan jenis tanah "Quartzite's, crystalline limestone, marble, crystallinerocks" untuk nilai maksimum yaitu 10.000 ohm-meter. Resistansi pentanahan harus ditentukan dengan membagi resistivitas tanah $\rho, \Omega . c m$, dengan 307. (IEEE Std. 142).

Rumus untuk menghitung resistansi terhadap tanah adalah dinyatakan sebagai berikut:

$$
R=\frac{\rho}{2 \pi L}\left(\ln \frac{4 L}{a}-1\right)
$$

Untuk n batang (rod):

dimana:

$$
R_{n}=F \times R \times \frac{1}{n}
$$

$$
\begin{aligned}
R= & \text { resistansi terhadap tanah dalam } \Omega \\
& \text { untuk batang tunggal. } \\
\rho= & \text { resistivitas tanah dalam } \Omega . m \\
L= & \text { panjang batang dalam } \mathrm{m} \\
a= & \text { setengah diameter batang } \\
& \text { pentanahan dalam } \mathrm{m} \\
n= & \text { jumlah batang vertikal dan diparelel } \\
& \text { bersama-sama } \\
F= & \text { faktor perkalian }
\end{aligned}
$$

Untuk sistem pentanahan $2-24$ batang ditempatkan satu batang panjang bagian dalam satu garis, segitiga berongga, lingkaran, atau persegi akan memberikan resistansi pentanahan dibagi dengan jumlah batang dan faktor kali $F$.

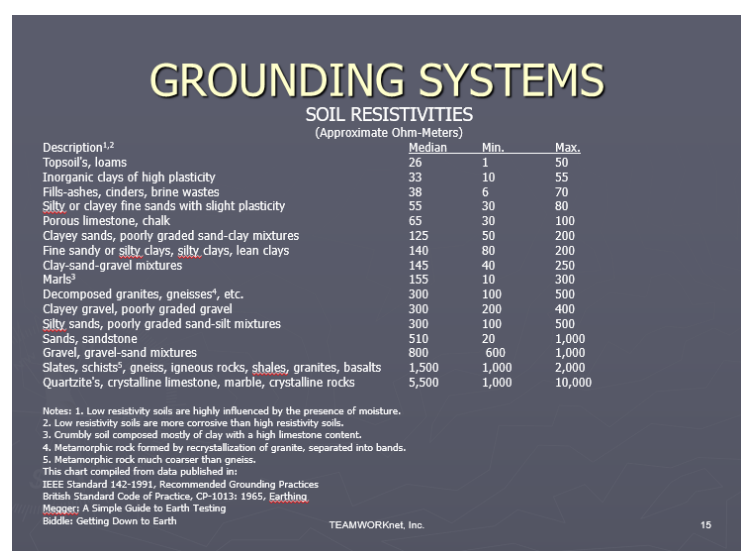

Gambar 3. Soil resistivity (Good Grounding Practices, A Brief Introduction to the Basics of ElectricalGrounding for Power Systems by Harry J. Tittel, E.E.)

\begin{tabular}{|c|c|}
\hline Number of rods & F \\
\hline 2 & 1.16 \\
\hline 3 & 1.29 \\
\hline 4 & 1.36 \\
\hline 8 & 1.68 \\
\hline 12 & 1.80 \\
\hline 16 & 1.92 \\
\hline 20 & 2.00 \\
\hline 24 & 2.16 \\
\hline
\end{tabular}

Gambar 4. Multiplying Factor F for Multiple Rods (IEEE Std. 142)

\section{b. Hasil Perhitungan}

Dalam perhitungan sebagai berikut, diketahui data berikut:

$\mathrm{L}=10 \mathrm{ft}(3 \mathrm{~m})=300 \mathrm{~cm}$

$a=1 / 2(3 / 4$ in $)=1 / 2(19,05 \mathrm{~mm})=0,9525$

$\mathrm{cm}$

$\rho=10.000 \Omega \cdot m$

sehingga diperoleh,

$R=\frac{\rho}{2 \pi L}\left(\ln \frac{4 L}{a}-1\right)$

$R=\frac{10000 \times 10^{2} / 307}{2 \times \pi \times 300}\left(\ln \frac{4 \times 300}{0.9525}-1\right)$

$R=\frac{3257,329}{1884,9556}\left(\ln \frac{1200}{0.9525}-1\right)$

$R=\frac{3257,329}{1884,9556}(6,137)=10,6081 \Omega$

Data resistivitas tanah di atas ditentukan dari jenis tanah Quartzite's, crystalline limestone, marble,crystalline rocks. (Good Grounding Practices, A Brief Introduction to the Basics ofElectrical Grounding for Power Systems by Harry J. Tittel, E.E. and reprinted from IEEE 
Standard142-1991, Grounding Practices; British Standard Code of Practice, CP-1013:1965, Earthing; Megger: A Simple Guide to Earth Testing; Biddle: Getting Down to Earth).

Untuk menurunkan nilai resistansi pentanahan diperlukan menggunakan rumus $\mathrm{n}$ batang pentanahan, misalnya dengan $n=3$, maka diperoleh resistansi pentanahan sebagai berikut:

$$
\begin{aligned}
& R_{n}=F \times R \times \frac{1}{n} \\
& R_{n}=1,29 \times 10,6081 \times \frac{1}{3} \\
& R_{n}=4,5615 \Omega
\end{aligned}
$$

Layout sistem pentanahan dapat dilihat pada Gambar 5 dan Gambar 6 berikut:

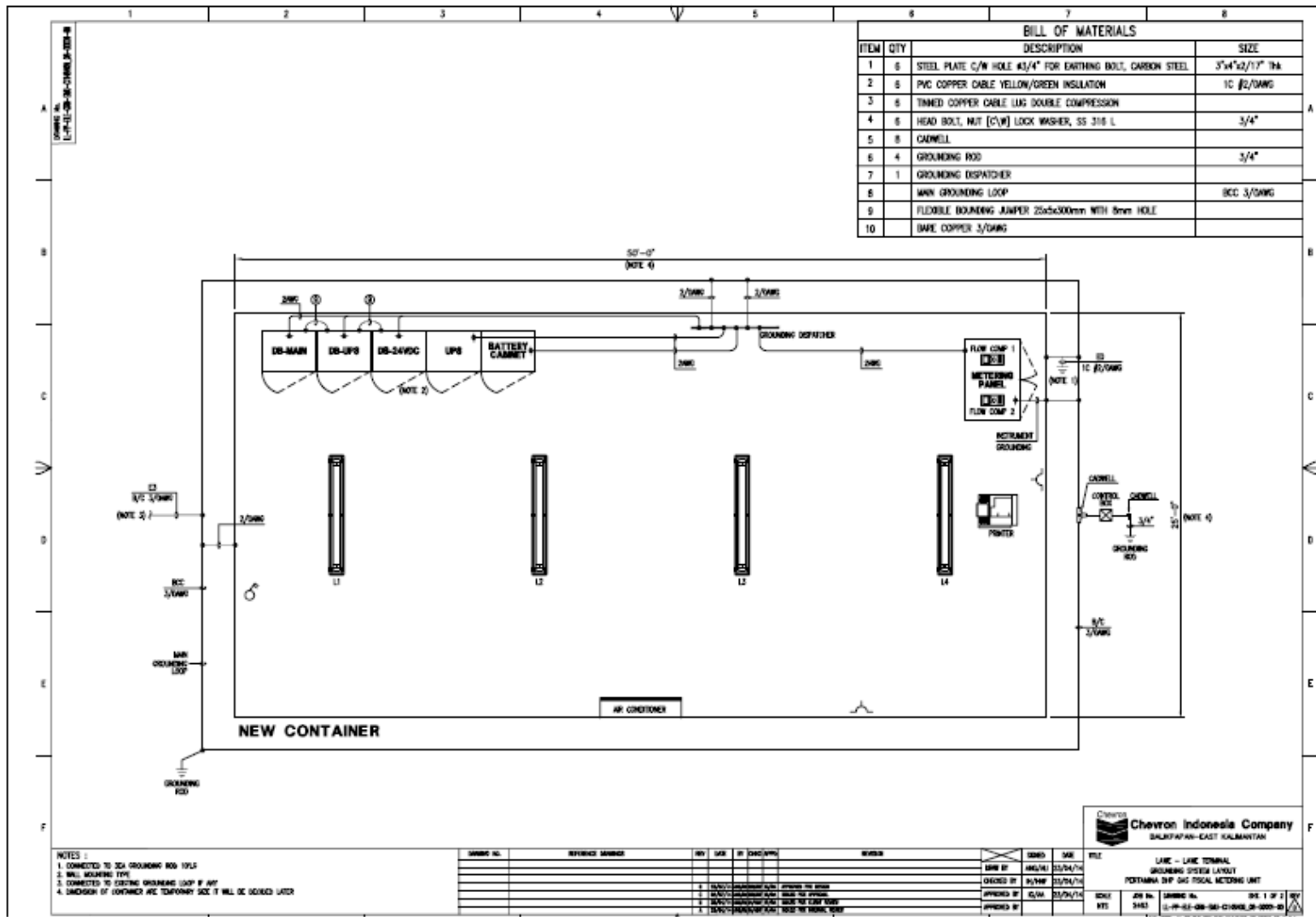

Gambar 5. Sistem Layout Pentanahan Terminal Lawe-Lawe Pertamina DHP Gas Fiscal Metering Unit 


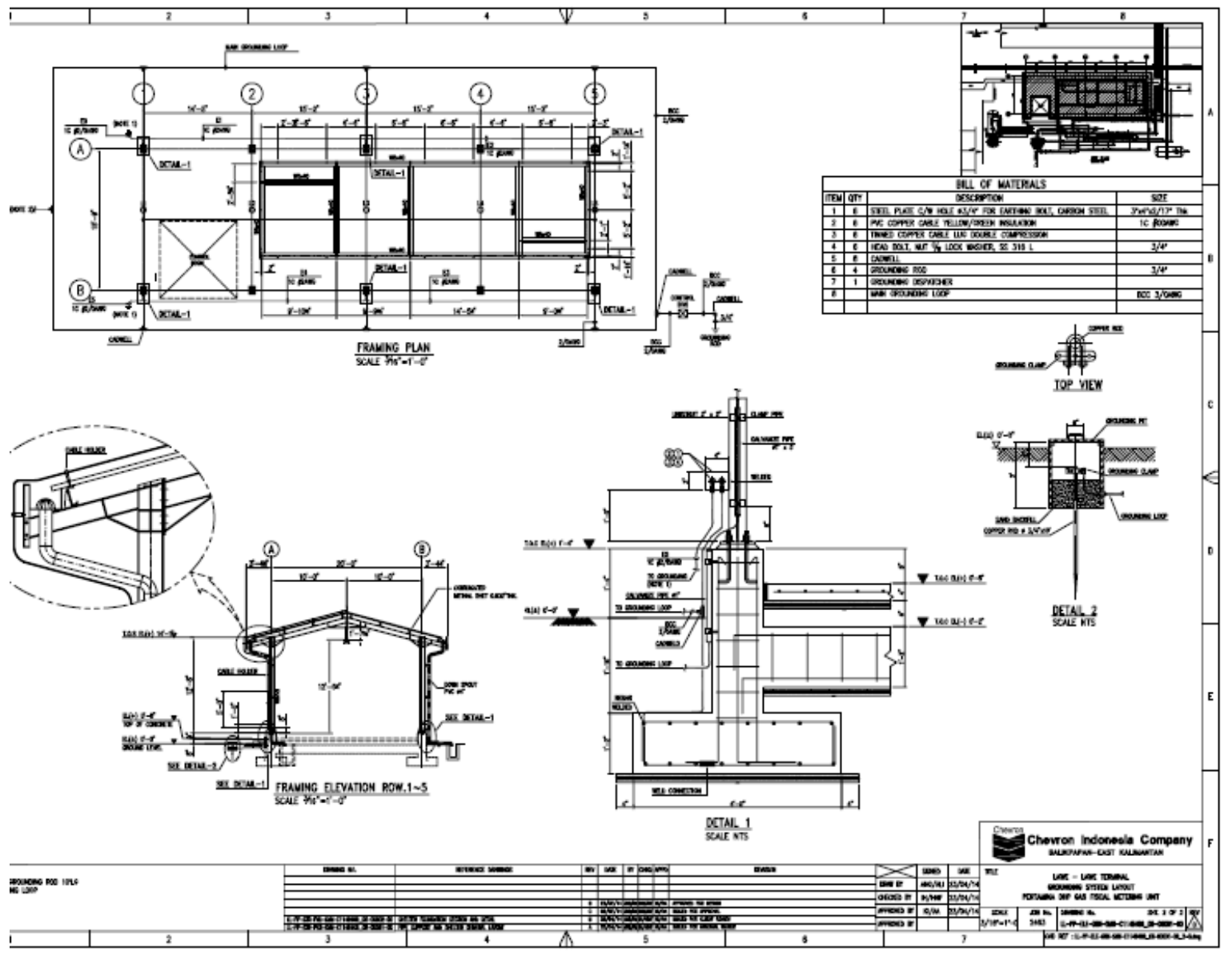

Gambar 6. Sistem Layout Pentanahan Terminal Lawe-Lawe Pertamina DHP Gas Fiscal Metering Unit

\section{Kesimpulan}

Berdasarkan data yang dipilih sebagai berikut:

$\mathrm{L}=10 \mathrm{ft}(3 \mathrm{~m})=300 \mathrm{~cm}$

$a=1 / 2(3 / 4$ in $)=1 / 2(19,05 \mathrm{~mm})$

$=0,9525 \mathrm{~cm}$

$\rho=10.000 \Omega . m$

Diperoleh hasil perhitungan untuk nilai resistansi pentanahan yaitu $10,6081 \Omega$ untuk batang tunggal dan $4,5615 \Omega$ untuk $\mathrm{n}=3$ batang. Nilai resistansi pentanahan yang diperoleh tersebut masih dapat diturunkan dengan menambah jumlah batang pentanahan, sehingga dapat diperoleh nilai resistansi pentanahan sekecil mungkin.

Untuk proteksi petir, jarak perlindungan horizontal d untuk tiang tunggal adalah 19,26 m dan jarak kilatan samping (sideflash distance) adalah 0.83 $\mathrm{m}$, sehingga untuk panjang struktur bangunan yang harus mendapakan perlindungan dengan proteksi petir $21 \mathrm{~m}$ diperlukan 2 unit proteksi petir yang harus dipasang di atas atap struktur bangunan (shelter).

\section{Referensi}

Anonim. 2003. Grounding system.ELC-EN900. Chevron USA Inc.

Anonim.2007. Recommended Practice for Grounding of Industrial and CommercialPower Systems. IEEE Std 142. Institute of Electrical and Electronics Engineers, Inc.

Anonim.2008.Standard for the Installation of Lightning Protection Systems.NFPA 780.2008Edition.

Tittel, Harry J., EE. 2001. Good Grounding Practices, A Brief Introduction to the Basics of ElectricalGrounding for Power Systems, TEAMWORKnet, Inc. 